ANUARIO DE ESTUdios MEDIEVALES

48/1, enero-junio de 2018, pp. 243-269

ISSN 0066-5061

https://doi.org/10.3989/aem.2018.48.1.08

\title{
LOS MERCADERES TOLEDANOS EN LOS REINOS HISPÁNICOS (1475-1520): UNA APROXIMACIÓN A PARTIR DEL OBSERVATORIO VALENCIANO*
}

\author{
THE MERCHANTS OF TOLEDO IN THE HISPANIC KINGDOMS (1475-1520): \\ AN APPROACH FROM THE VIEWPOINT OF VALENCIA
}

DAVID IGUAL LUIS

Universidad de Castilla-La Mancha http://orcid.org/0000-0002-4472-0961

\begin{abstract}
Resumen: Este artículo examina la presencia de los mercaderes toledanos en los reinos hispánicos en el periodo 1475-1520. Se basa esencialmente en el observatorio que ofrecen la ciudad de Valencia y sus fuentes, donde menudean las citas de actividades toledanas. Comienza con un balance contextual de las familias y las compañías que protagonizaron el comercio fuera de Toledo y, después, se centra en dos aspectos: los espacios donde actuaron los toledanos, a partir de una serie de letras de cambio testimoniadas en Valencia, y las relaciones entre los toledanos y otros grupos mercantiles gracias al estudio de casos y episodios concretos.
\end{abstract}

Palabras clave: mercaderes; Toledo; reinos hispánicos; familia; compañía mercantil.

Abstract: This article examines the presence of the merchants of Toledo in the Hispanic kingdoms in the period 1475-1520. It is based on the viewpoint offered by the city of Valencia and its sources, where references to the activities of Toledo citizens are frequent. It begins with a contextual summary of the families and companies that were prominent in trade outside Toledo and, subsequently, focuses on two aspects: the areas where Toledo merchants acted, based on a series of bills of exchange witnessed in Valencia, and the relationship between the merchants of Toledo and other groups through the study of specific cases and episodes.

Keywords: merchants; Toledo; Hispanic kingdoms; family; merchant company.

\section{SUMARIO}

1. Introducción.- 2. Un balance contextual acerca de los mercaderes toledanos y su proyección externa.- 3. Desde Valencia: el mapa de las actividades toledanas a través de las letras de cambio.- 4. Variedad y ambivalencias de las relaciones entre comerciantes.- 5. Conclusiones.- 6. Apéndice.- 7. Bibliografía citada.

\footnotetext{
${ }^{*}$ Este trabajo forma parte del proyecto I+D+i HAR2013-44014-P (2014-2017), financiado por el Ministerio de Economía y Competitividad del Gobierno de España y dirigido desde la Universidad Complutense de Madrid por María Asenjo González.

Cómo citar este artículo: Igual Luis, David (2018), Los mercaderes toledanos en los reinos hispánicos (1475-1520): una aproximación a partir del observatorio valenciano, "Anuario de Estudios Medievales" 48/1, pp. 243-269. https://doi. org/10.3989/aem.2018.48.1.08

Copyright: (C) 2018 CSIC. Este es un artículo de acceso abierto distribuido bajo los términos de la licencia de uso y distribución Creative Commons Reconocimiento 4.0 Internacional (CC BY 4.0).
} 


\section{INTRODUCCIÓN ${ }^{1}$}

A finales de la Edad Media, las características de los mercaderes toledanos y sus actividades en los reinos hispánicos son realidades bien acreditadas por la investigación. Hay que admitir, sin embargo, que la historiografía que las ha abordado es menos profusa que la que ha tratado otros grupos mercantiles. Sea como fuere, a esas características y esas actividades he dedicado ya un par de trabajos, en los que he combinado el resumen de los conocimientos previos con la aportación de documentación inédita ${ }^{2}$. Contando con estos dos estudios míos como puntos iniciales, el objetivo del presente artículo es más modesto. En él pretendo solo ahondar en las dinámicas generadas en la Península Ibérica por los operadores toledanos y añadir nuevas informaciones, a partir siempre del observatorio que ofrecen la ciudad de Valencia y sus fuentes. A estas añadiré como complemento algunos pocos documentos castellanos. Pero la centralidad en Valencia no evitará que, como contexto imprescindible, brinde de entrada un balance somero acerca de cómo se concretó la presencia toledana en el conjunto de tierras ibéricas.

En paralelo, dos acotaciones enmarcarán los argumentos que desarrollaré. La primera es cronológica, puesto que la fase que centrará aquí mi interés cubre la transición entre los siglos XV y XVI, grosso modo entre 1475 y 1520. En estos años se unen el aumento de la documentación disponible en muchas áreas hispánicas para analizar el comercio, la consolidación de la expansión mercantil castellana dentro de los prolegómenos de la denominada "Primera Edad Global"3 y el papel relevante que Toledo, pero también Valencia, jugaron en el panorama económico peninsular. Aunque sea con diferencias entre las dos ciudades, dicho papel se justifica por el peso demográfico de ambas, por las funciones que desempeñaron en términos productivos y comerciales y por sus respectivos roles territoriales ${ }^{4}$. Así, el eje Toledo-Valencia logró entonces un fuerte protagonismo, que como se verá no fue en absoluto exclusivo para los operadores que circulaban por la propia península.

La segunda acotación es temática, ya que muchos aspectos que expondré aspiran a brindar sugerencias acerca del problema más amplio que focaliza el monográfico donde se incluye este artículo: los procesos de jerar-

${ }^{1}$ Abreviaturas utilizadas: ACT $=$ Archivo de la Catedral de Toledo; $\mathrm{AGS}=$ Archivo General de Simancas; AHPV = Archivo Histórico Provincial de Valladolid; AMV = Archivo Municipal de Valencia; ARV = Archivo del Reino de Valencia; doc./docs. = documento/documentos.

${ }^{2}$ Igual, en prensa a y, especialmente, Igual, en prensa b.

${ }^{3}$ Casado 2012b.

${ }^{4}$ Baste repasar las abundantes informaciones que, sobre Toledo y Valencia, se sintetizan en Ladero 2017. 
quización urbana, en mi caso observados a escala de la Península Ibérica y en el periodo considerado. Para priorizar precisamente algunas circunstancias de esa jerarquización, prestaré atención a los espacios de actuación de los mercaderes toledanos y a su relación con otros colectivos comerciales, establecida a partir de las bases personales y familiares que sostuvieron la proyección toledana fuera de la capital del Tajo. Estos contenidos se han seleccionado por varias razones. Primera, porque el ámbito espacial donde se insertaban los movimientos de los mercaderes de una ciudad reflejaba en parte su potencial económico, tanto el global de la misma ciudad como el particular de sus habitantes. Después, porque el mapa de esos movimientos solía concentrarse en zonas de interés comercial, que atraían a su vez a otras comunidades mercantiles y que, por tanto, ocupaban una categoría destacada en el mundo de los negocios. Finalmente, porque los vínculos que se articulaban entre los diversos grupos de operadores, a través de la colaboración o la rivalidad y del normal desarrollo de la vida económica o los episodios de conflicto, pueden permitir deducir si tales grupos concurrían en pie de igualdad o, por el contrario, con condiciones diferenciadas en sus capacidades técnicas y empresariales.

En el seno de las distintas perspectivas que acabo de apuntar, examinar el ejemplo de los toledanos en el entorno de 1500 implica fijarse en unos mercaderes que, al igual que muchos colegas de profesión, venían consiguiendo desde atrás cotas relevantes de diversificación y expansión de intereses (comerciales, industriales y financieros), de integración por numerosas vías con los poderes políticos y sociales y de cierta sofisticación en sus estructuras asociativas. También estos castellanos, para conformar compañías mercantiles y desplegar sus actividades económicas, recurrieron con intensidad a la familia y a la construcción de redes complejas de relación. Es verdad que, desde finales del Cuatrocientos, las raíces judeoconversas de una parte mayor o menor de los agentes del comercio toledano, reales o supuestas, y la implantación de la Inquisición perturbaron la acción de estos mercaderes y hasta alteraron o matizaron sus rasgos. Pero, desde luego, no la impidieron en absoluto ${ }^{5}$.

\section{UN BALANCE CONTEXTUAL ACERCA DE LOS MERCADERES TOLEDANOS Y SU PROYECCIÓN EXTERNA}

En Toledo como por doquier, la irradiación económica externa de los mercaderes corrió en buena medida a cargo de operadores grandes y medianos que, habitualmente, se ocupaban menos de las tareas del abastecimiento

\footnotetext{
${ }^{5}$ Igual, en prensa b.
} 
ciudadano y más del comercio regional e interregional, al mover una gama de productos y capitales que podía ser extensa, desbordar las fronteras jurisdiccionales y depender solo en parte de las necesidades del lugar de nacimiento o residencia ${ }^{6}$. De hecho, los estudios efectuados hasta ahora han enfatizado ya quiénes serían, siempre para la fase 1475-1520, los principales mercaderes toledanos que actuaron más allá de su ciudad. En el conjunto cabe destacar a los que se agrupaban en familias como Acre, Cota, Franco, de la Fuente, Hurtado, Husillo, Jarada, Ortiz, San Pedro y de la Torre. Para comprobarlo, baste acudir a los elencos conocidos de gentes de Toledo que negociaron entonces en algunos focos económicos hispanos importantes. En Valencia se sabe que, de 1487 a 1497, fueron alrededor de cuarenta los mercaderes de esa procedencia que intervinieron en su mercado, de manera permanente o esporádica, y que tuvieron como eje de atención primordial el tráfico de paños y materias primas textiles, sobre todo del sector sedero ${ }^{7}$. Mientras, la presencia toledana en Valladolid, Medina del Campo y Medina de Rioseco fue también relevante. Por ello no es extraño que, entre 1515 y 1521, se hayan atestiguado asimismo en torno a cuarenta mercaderes de Toledo tratando cada año en Medina del Campo, en sus ferias de mayo y octubre ${ }^{8}$. Más en general, hasta 375 comerciantes de la capital del Tajo (bastantes, sin embargo, de origen italiano) han sido registrados para la etapa 1486-1520 en los protocolos notariales de Valladolid y de ambas Medinas?.

Precisamente, un repaso por las fuentes del periodo evidencia la repetición en muchas ciudades de determinados nombres toledanos. El fenómeno es usual en los ambientes mercantiles. Pero, comparativamente, creo que la reiteración se da con los toledanos de forma muy acusada ${ }^{10}$. En realidad, la decena de apellidos que he reseñado y unos pocos más constituirían la base del colectivo de mercaderes toledanos que se movía fuera de su ciudad. Esta circunstancia complica la investigación, y no solo por el problema de la homonimia (que existe dentro de los toledanos y entre los toledanos y otros castellanos). También porque, si nos fijamos en varias plazas comerciales y en varios

${ }^{6}$ Ladero 2010, p. 65.

${ }^{7}$ Igual, en prensa a.

${ }^{8}$ Abed Al-Hussein 1986, p. 57.

${ }^{9}$ Carvajal, et al. 2015 , pp. 50 y 823-826.

${ }^{10}$ Este hecho podría ser una consecuencia de los problemas acarreados a los judeoconversos toledanos, muchos de ellos mercaderes, por los conflictos y la represión a los que se enfrentaron. Es sabido que tales problemas, junto a ciertos comportamientos tradicionales, llevaron a los conversos a adoptar estrategias como el ocultamiento o el falseamiento de sus orígenes, la creación de nuevos linajes, el abandono y el cambio (o intercambio) de apellidos, la repetición de homonimias incluso con la órbita no conversa, la mezcla de enlaces matrimoniales y la dispersión física de las parentelas (López 2007, p. 201; Martz 1988, pp. 121-122 y 126; Martz 2002, pp. 76-78). 
tipos documentales, es difícil en ocasiones deducir si dos mercaderes con el mismo nombre en dos lugares son una misma persona o no, incluso aunque la correlación de fechas y actividades haga plausible su equiparación.

En cualquier caso, la decena de apellidos y poco más que he comentado ofrece la imagen de un universo de negocios toledano, exterior a la propia Toledo, que sería en principio algo reducido. No obstante, hay que ir con cuidado con esta primera impresión. Como confirma la historiografía, las familias toledanas que integraban a mercaderes solían poseer composiciones amplias y acabar divididas en diversas ramas, incorporando así a numerosos miembros con estatus socio-profesionales y económicos muy diferenciados. De paso, esto quiere decir que, si un comerciante se llamaba Acre, Cota o de la Fuente, puede que ello no significara mucho de entrada. Por tanto, que un individuo poseyera un cierto apellido no debe llevarnos a prejuzgar el potencial de su currículo ${ }^{11}$. Como es lógico, únicamente el seguimiento pormenorizado de su carrera aportará luz sobre la magnitud de sus actuaciones.

Algunas trayectorias han sido resaltadas por los expertos. Es lo que ocurre con Alonso de Toledo, oriundo de esta ciudad, ya a mediados del XV. Este mercader se avecindó en Burgos, desde donde tejió una intrincada red de vínculos comerciales que abarcó toda Castilla y, especialmente, el eje BurgosToledo $^{12}$. Con más detalle se ha dibujado la historia de Francisco de Santo Domingo, un mercader toledano de raíz judeoconversa que nació aproximadamente a inicios de la década de 1460 y murió hacia 1517. Francisco fue perseguido por la Inquisición y sufrió la cárcel entre 1506 y 1508, aunque finalmente logró librarse de la condena. Durante el tiempo de su prisión escribió una autobiografía, con la que Linda Martz elaboró el relato de su vida ${ }^{13}$. En clave mercantil, este relato muestra a Francisco como un agente que acostumbró a rodearse en sus operaciones por un círculo de relaciones formado en lo sustancial por sus parientes (algunos afectados asimismo por el acoso inquisitorial), por otros conversos y por personas bien situadas en los niveles de la sociedad e incluso la administración.

Francisco comenzó a construir ese círculo desde joven, cuando entró al servicio de su tío Sancho de Toledo - un destacado tratante de tejidos- para ganar experiencia en el mundo del comercio. También el padre y el que sería suegro de Francisco se dedicaban al intercambio textil, aunque Sancho fue en su momento el mercader más prominente del grupo y progresó gracias a la importación de paños caros de calidad que eran vendidos a la corte real y

${ }^{11}$ López 2007, pp. 198 y 201; Martz 1988, p. 127.

${ }^{12}$ Puñal 2014, p. 120.

${ }^{13}$ Martz 2002, pp. 96-97 y 113-125. 
a la nobleza castellana. Bajo el patrocinio de Sancho, Francisco aprendió el oficio, viajó a plazas distantes (a Sevilla y Andalucía en 1477, a Portugal y Madeira durante el decenio siguiente) y entabló contactos que debieron servirle después, cuando estableció autónomamente sus propias empresas. En ellas contó con socios como su suegro, su cuñado, algún hermano y otros familiares. A través de sus compañías, Francisco llegó a responsabilizarse del abastecimiento de las carnicerías de Toledo en los primeros años del XVI. Pero, sobre todo, se concentró en el tráfico de lana y tejidos con un radio de acción que empezaba en Toledo, continuaba en los pueblos de alrededor, alcanzaba Andalucía (Jerez de la Frontera, Écija o Carmona) y concluía en las ferias de Medina del Campo. Este itinerario permitió a nuestro personaje acumular una riqueza que era como mínimo confortable antes de su arresto en 1506, lo que le brindó la posibilidad de casar a sus hijos con otros descendientes conversos de familias con similares profesiones y categorías sociales.

Lo que trasluce la crónica de Francisco de Santo Domingo no debe sorprender, en particular por lo que atañe a sus índices de extensión territorial de negocios y de complejidad de la trama familiar y societaria. Dichos índices son prototípicos de nuevo en determinados sectores mercantiles. Por lo que se refiere en concreto a la interconexión entre familia y comercio, este es un elemento suficientemente demostrado a escala hispánica y europea y que es innecesario recalcar. Solo cabría recordar que, también para los toledanos, se ha corroborado en muchos casos que no existía una visión empresarial fuera de la parentela y que la gestión tanto de la familia como de las compañías mercantiles podía pertenecer a un esquema único de socialización ${ }^{14}$. A pesar de esto, quizá es más pertinente insistir, en línea con los matices que se han argumentado recientemente, en la insuficiencia final de las interpretaciones que se limitan a afirmar la correlación entre las características de las empresas y la entidad y proyección de las familias que estaban detrás de ellas. En último extremo, los mercaderes se apoyaban tanto en los lazos familiares como en marcos de solidaridad más amplios ${ }^{15} \mathrm{o}$, por expresarlo con mayor precisión, sus firmas solían ampararse en la organización de una serie eficiente de relaciones económicas y personales, extraeconómicas, que contemplaban los vínculos de familia, pero también variables como la amistad, la conveniencia o la confianza y hasta el reconocimiento de la competencia profesional y la habilidad para ampliar -geográfica y sectorialmente- la esfera de actuación de cada compañía ${ }^{16}$.

\footnotetext{
${ }^{14}$ Alonso 2005, p. 15; Martz 2001, p. 164.

${ }^{15}$ Casado 2012a, pp. 21 y $25-26$.

${ }^{16}$ Orlandi 2016, pp. 124, 142 y 145-146.
} 
Entre los mercaderes de Toledo no faltan los indicios de esta multimensionalidad en la conformación societaria, muy en especial a la hora de admitir aportaciones de capital de diversos operadores, no integrados siempre en una misma parentela. Entre los de la Fuente, por ejemplo, destacan entre el XV y el XVI las actividades de la rama de Rodrigo de la Fuente y sus hijos Diego, Juan y Alonso de la Fuente. Estas se desparramaron básicamente por el espacio comprendido entre Toledo, Valencia, Medina del Campo y Andalucía. Afectaron a infinidad de asuntos comerciales y financieros, incluyendo los tratos con la corte real y el interés por gestionar rentas de la monarquía. Entre ellas, la renta de la seda de Granada, en cuyo arrendamiento irrumpieron los de la Fuente en 1505. En el conjunto de los negocios, muchos fueron asumidos bajo la titularidad exclusiva de los miembros de la familia. Pero, en realidad, los de la Fuente solían moverse asociados a más toledanos: los Acre, los Jarada y, sobre todo, los de la Torre. Con estos otros apellidos llegaron a emparentar y a fundar alianzas económicas y empresariales de distinto significado ${ }^{17}$. Incluso mantuvieron contactos con agentes de otros orígenes. Así se justifica que, en 1503, en concreto Diego de la Fuente y Alonso de la Torre, vecinos de Toledo, fueran fiadores del denominado "banco de Valencia" de Francesco Palomar (genovés de Valencia) y Pedro Sánchez (de Zaragoza). Esta fianza se otorgó en el transcurso de un pleito que dicho "banco" tuvo que afrontar entonces, por la saca fraudulenta de moneda de oro castellana. En el conflicto se vieron también envueltos los mercaderes genoveses que representaban al "banco" en Toledo ${ }^{18}$.

Justamente, los enlaces entre algunas de las familias toledanas que acabo de señalar se ven ratificados, a inicios del XVI, a través de una compañía instalada esencialmente en el eje Toledo-Valencia para el comercio sedero, pero que extendió en paralelo los negocios a Medina del Campo y su entorno. En 1513, las cuentas de la disolución de la empresa avalan que esta disponía de un capital de 1.740.964 maravedís, distribuidos en varios socios. El principal era Alonso Sánchez de Toledo, con el 36 \% de la inversión. Le seguían los hermanos Francisco y Fernando de la Torre, con el $21 \%$ y el $17 \%$ del total, respectivamente. Estaban por último Lope García de Acre (16\%) y Francisco de la Fuente $(10 \%)$. En definitiva, cinco titulares de cuatro apellidos diferentes constituían el soporte de esta asociación ${ }^{19}$. Es una situación parangonable

\footnotetext{
${ }^{17}$ Alonso 2005; Igual, en prensa b; Soria 2016, pp. 425-427.

${ }^{18}$ Ladero 1987, p. 572. Sobre la fianza de Diego de la Fuente y Alonso de la Torre, véase asimismo AGS, Consejo Real de Castilla, legajo 60, $\mathrm{n}^{\circ}$ 6. Acerca del "banco de Valencia" y su estructura de negocios y relaciones, puede recurrirse a la referencia de Ladero en esta nota o a Igual 1996, pp. 188-189.

${ }^{19}$ Rozas, en prensa. Los datos de la compañía indicada provienen de un documento notarial del Archivo Histórico Provincial de Toledo, que se encuentra aún en fase de estudio por parte de este autor.
} 
a la deducida a finales de 1507 para otra compañía toledana, radicada en la propia ciudad del Tajo, que se cimentó sobre el capital de siete socios: cuatro pertenecientes a la familia Cota y tres a la familia de las Cuentas. En esta ocasión, el activo de la empresa sumaba 3.231.375 maravedís y se nutría, entre otros intereses, de la explotación de inmuebles, del negocio de las rentas y la fiscalidad urbanas y de la compraventa textil. En el inventario de existencias de la firma, siempre de 1507, se hallaban paños, granas, rasos, mantillas, holandas y materias tintóreas, productos que se decía a veces que provenían de Londres, Valencia, Cuenca o la misma Toledo ${ }^{20}$.

\section{DESDE VALENCIA: EL MAPA DE LAS ACTIVIDADES TOLEDANAS A TRAVÉS DE LAS LETRAS DE CAMBIO}

Como vemos, gracias a sus operaciones de diverso signo, los mercaderes toledanos podían obviamente acceder a artículos de numerosas procedencias, también de fuera de la Península Ibérica. Sin embargo, basta echar una ojeada a las páginas previas para fijarnos en que, en términos de actuación y/o establecimiento territorial, los hechos e ideas que ya he recogido reflejan una atención prioritaria de los toledanos y sus compañías por los reinos hispánicos en general y, dentro de ellos, por algunos ámbitos específicos. Este sería el caso de Valencia, cómo no, si bien todavía no hay un balance concluyente tanto de lo que significó el mercado valenciano para el conjunto de los negocios toledanos como, a la inversa, de lo que aportaron los toledanos a la economía de la ciudad y el reino de Valencia. Por lo que respecta a la capital valenciana sí se ha corroborado ya, al menos, que esta fue utilizada durante el Cuatrocientos por los toledanos como plaza de residencia permanente o temporal, de contratación textil, de aprendizaje artesanal y de transferencia financiera mediante el giro de letras de cambio ${ }^{21}$.

De acuerdo con la finalidad de mi estudio, creo conveniente detenerme en particular sobre tales instrumentos cambiarios. Desde Valencia, la estructura de los mismos y la participación en ellos de los toledanos ayudan a trazar una cierta geografía de los espacios de intervención de estos mercaderes, que superaban con mucho -incluso desde el propio observatorio valenciano- el mero circuito Toledo-Valencia. Por si es necesario, recuerdo que la letra de cambio era un mecanismo que servía para transportar dinero de ciudad a ciudad: una ciudad era el lugar de redacción y emisión de la letra;

${ }^{20}$ Carvajal 2012, pp. 59-64.

${ }^{21}$ Igual, en prensa $b$. 
la otra era donde se recibía y se pagaba o reclamaba, en este último caso a través del acto jurídico del protesto, que se efectuaba ante notario. Cada letra incorporaba cuatro vértices de actuación, que podían corresponderse con otros tantos agentes económicos: dos en la ciudad de emisión (alguien que pagaba y alguien que cobraba) y dos en la de recepción (lo mismo: alguien que pagaba y alguien que cobraba).

Enrique Otte mostró hace años que, a consecuencia del esquema que he sintetizado, las letras de cambio eran útiles para dibujar un mapa de asentamientos mercantiles. Otte, con las letras que localizó en los fondos notariales de Sevilla, diseñó la red de los genoveses en España entre 1494 y $1584^{22}$. Un intento igual, también para los genoveses en España, se realizó para una fase anterior y más corta, pero a partir de las letras remitidas a Valencia y que se copiaron en los registros del notario valenciano Jaume Salvador entre 1475 y 1500: un total de 2.299, reproducidas en recibos o, normalmente, protestos $^{23}$. Justo el recurso a estas segundas fuentes valencianas brinda la posibilidad de aplicar a los mercaderes toledanos un planteamiento similar. De hecho, el sondeo entre los 2.299 cambios de 1475-1500 ha dado como resultado 64 letras que implicaron con seguridad a operadores de Toledo: la primera es de 1477 y la última de 1500, si bien la serie solo es más constante desde 1484-1485. Dicha implicación se produjo en cualquiera de los cuatro vértices que he descrito, tanto en Valencia (el centro de recepción de todos estos giros monetarios) como en otras plazas desde las que se enviaron transferencias a la capital mediterránea. A los toledanos se les anota en esta documentación con denominaciones o titularidades que aluden a mercaderes singulares o a asociaciones de dos o más mercaderes. Los detalles de estas titularidades, y de los lugares donde han sido testimoniadas, figuran en el cuadro del apéndice final ${ }^{24}$.

Estamos lejos de poseer una imagen nítida sobre lo que suponía el uso de las letras dentro de los balances empresariales toledanos o, incluso, sobre la posición que ocupaban los comerciantes de Toledo en el universo general de la circulación cambiaria. Desde luego, si hacemos caso a la colección valenciana de letras del último cuarto del siglo $\mathrm{XV}$, esa posición sería secundaria. Así lo denota, en la citada colección, la escasa cifra de los cambios que afectaron a toledanos (64 frente al total de 2.299) y, también, que la función de estos no parece de ningún modo equiparable -ni en cantidad ni en calidad-a la desempeñada por quienes sí fueron entonces los grandes fundamentos de

\footnotetext{
${ }^{22}$ Otte 1986.

${ }^{23}$ Igual, Navarro 1997.

${ }^{24}$ También en el cuadro se verán las referencias archivísticas de las 64 letras de cambio que acabo de reseñar.
} 
este mundo financiero en Valencia: mercaderes valencianos y catalanes, por un lado; mercaderes ligures y toscanos, por el otro ${ }^{25}$.

Sea como fuere, la presencia toledana en las letras de Valencia demuestra al menos que, coincidiendo con lo que sucedía en la época en el resto del comercio castellano ${ }^{26}$, también los toledanos emplearon con alguna asiduidad la herramienta cambiaria. Lo hicieron por el múltiple sentido (financiador, crediticio y especulativo) que otorgaron a las letras los ambientes económicos en que ellos mismos estaban insertos, o quizá, en paralelo, por la situación de su ciudad de origen (Toledo) en el seno de las relaciones financieras peninsulares. Felipe Ruiz Martín afirmó hace un tiempo que Toledo, aparte de ser foco artesanal y mercantil, alcanzó desde inicios del XV la categoría de plaza de cambios por influencia tanto de los negociadores italianos como de las conexiones mantenidas hacia la Corona de Aragón ${ }^{27}$. En esa línea, lo cierto es que Toledo todavía se mantenía entre finales del siglo XV y principios del XVI como un ámbito, primero, de interés financiero para los mercaderes italianos residentes en área ibérica y, después, de tráfico cambiario hacia el espacio aragonés ${ }^{28}$. De estas condiciones se aprovecharon los propios operadores de Toledo, ya fueran los mercaderes que terciaban desde la urbe en el giro de letras hacia otros lugares ${ }^{29}$, ya fueran los cambistas de la ciudad que, junto a las tareas que asumían dentro de Toledo, podían intervenir también en la gestión de cambios externos ${ }^{30}$.

Volviendo a las 64 letras de Valencia que he indicado y a los detalles del apéndice, la actuación cambiaria de los toledanos se manifiesta repartida por trece plazas. Las ordeno según el número de titularidades, individuales o colectivas, que pueden adscribirse a cada una. El ranking es encabezado por Valencia con 23 titularidades. Le siguen Medina del Campo con 16 y la misma Toledo con 11. Cierran la lista Sevilla con tres titularidades, Villalón con dos y, con una cada una, Alcalá de Henares, Barcelona, Burgos, Medina de Rioseco, Requena, Roma, Segovia y Valladolid.

${ }^{25}$ Compruébese el papel de estos otros grupos mercantiles en Valencia, dentro del conjunto de 2.299 letras de 1475-1500, en Igual 1998, pp. 422-428.

${ }^{26}$ Carvajal 2015b, pp. 89-96; Casado 2015, pp. 293-305.

${ }^{27}$ Ruiz 1995, p. 190.

${ }^{28}$ Igual 1997, pp. 143 y 150-151; Ladero 1987, pp. 581-582.

${ }^{29}$ Como hacia Valencia, según corrobora el cuadro del apéndice final con las titularidades de mercaderes toledanos que aparecen en la misma Toledo.

${ }^{30}$ Carvajal 2015a, p. 33; Ladero 1987, p. 582. En ambos trabajos son citados algunos cambistas de Toledo de inicios del XVI: Juan Díaz (1502), Francisco de Madrid (1502), Sancho Ortiz (1519) y Juan de Toledo $(1502,1503,1508)$. Otras fuentes permiten añadir nuevos sujetos de las postrimerías del XV: ACT, Pergaminos, 0.9.E.1.33, 1483-XI-11 (Miguel García); AGS, Registro General del Sello, 1494-IV-i? (f. 295: Alfonso Sánchez) y 1494-XII-2 (f. 86: Lope de Toledo). 
Un simple vistazo a los datos del cuadro final ilustrará que, en realidad, hay nombres de toledanos que se repiten en varias localidades. Además, y aunque la documentación utilizada imposibilita saber qué impulsó la elaboración de las letras que he considerado, cabe pensar que algunas de ellas respondían a motivaciones ligadas a los vínculos de los toledanos con las redes fiscales y de abastecimiento de la monarquía en Castilla. La hipótesis me viene sugerida, en general, por lo intensos que fueron esos vínculos ya como mínimo desde mediados del siglo $\mathrm{XV}^{31} \mathrm{y}$, en concreto, por la identificación en el cuadro de personajes que formaron parte efectivamente de las redes mencionadas $^{32}$. Por tanto, si estoy acertado, las letras que pertenecieran a este terreno de relación con la monarquía escaparían a las lógicas que dependían, meramente, o del asentamiento de los mercaderes en determinadas zonas o de los rasgos socioeconómicos de estos lugares. A la postre, las dos circunstancias que estoy señalando (repetición de nombres y posible conexión con la corona) matizan el valor de mi sondeo de cara a fijar una cartografía de los establecimientos mercantiles toledanos. Con todo, dicho sondeo ofrece indicios de mayor o menor relieve sobre la cuestión, en especial si los cotejamos con otras informaciones.

De entrada, las trece plazas aducidas en el apéndice son hispanas, castellanas en su inmensa mayoría, excepto Roma. Las mismas fuentes cambiarias valencianas permiten detectar, aparte, alguna actividad toledana desde Lyon $^{33}$. Pero todo vuelve a ratificar la impresión de que es en la Península Ibérica donde los mercaderes toledanos focalizaron sus intereses. En ella, el liderato que emerge de la tríada Valencia-Medina del Campo-Toledo no parece casual, aunque la acumulación de titularidades en Valencia se ve obviamente beneficiada (y desviada comparativamente al alza) porque la investigación realizada se ha basado justo en documentos valencianos. Que Toledo despuntara en la acción económica de nuestros operadores es normal, tanto por ser su punto de partida como por las funciones cambiarias que la ciudad ostentaba,

${ }^{31}$ Acerca del tema, conviene consultar Ortego 2014; 2015, sobre todo pp. 169-260. También Caunedo 1983; González 2016, pp. 93, 105-106, 130, 450 y 523.

${ }^{32}$ Serían casos como el de Alonso de Castro o Alonso de Castro Espanoche (sobre quien se aducen en el apéndice las correspondientes notas justificativas) o, asimismo, como los de Alonso de la Torre y Diego de la Fuente (desde varios lugares) o de Francisco de Torres (desde Requena). Sobre estos últimos se encontrarán noticias en la bibliografía de la nota anterior y en Igual, en prensa, a y b.

${ }^{33}$ En 1491 y 1492, tres letras remitidas de Lyon a Valencia, todas asumidas al completo (en sus cuatro vértices) por titulares italianos, contemplaron que el dinero de las mismas era a cuenta de Sancho de Toledo. Probablemente es el mismo operador a quien, en compañía de Alonso de Castro y calificados ambos como toledanos, se le debía computar en 1493 otra letra enviada de Sevilla a Valencia. Véase ARV, Protocolos, n 2007 (1491-VI-20), 2690 (1492-V-10, hay dos letras) y 2692 (1493-X-26). 
según he comentado hace un instante. Mientras, es muy conocido el fuerte movimiento comercial y financiero, también diversificado, que convergió en Valencia y en Medina del Campo y sus ferias durante la segunda mitad del Cuatrocientos. Un movimiento que, sin duda, atrajo a los toledanos y fue estimulado a la vez por estos. De ahí las altas cifras de mercaderes de Toledo que, como ya he expuesto, pueden hallarse en ambos sitios entre el XV y el XVI. No se olvide además que, específicamente en Medina del Campo, la de Toledo era una de las denominadas "Cuatro Calles" que reunían a los comerciantes de cuatro de las principales urbes pañeras castellanas, para favorecer la venta de sus tejidos. Las otras calles eran las de Cuenca, Segovia y Palencia ${ }^{34}$.

Al lado del protagonismo para los toledanos de los tres núcleos resaltados, las restantes plazas ibéricas descubiertas en el sondeo reafirman sus actuaciones en el Mediterráneo (Barcelona) y en la Meseta del Duero (Burgos, Medina de Rioseco, Segovia, Valladolid y Villalón), o revelan su presencia en espacios más centrales (Alcalá de Henares y Requena) y meridionales (Sevilla). Por pocas que sean las titularidades y las letras registradas en tales lugares $^{35}$, estos ayudan a perfilar la dispersión que adquirieron al final los negocios toledanos por buena parte de la península.

De hecho, avalando esa dispersión, la historiografía aporta más ámbitos desde los que trataron los agentes de Toledo, ya fuera en asuntos comerciales y/o de tráfico de dinero, siempre sobre todo en las décadas a caballo de 1500. Semejantes ámbitos, aunque diferentes a los reseñados en el apéndice, corroboran algunas de las direcciones ya vistas hacia las que se proyectó la economía de los toledanos. Es lo que ocurre con Madrid, verdadera antesala mercantil de Toledo; con Murcia, en el extremo del camino Toledo-Cartagena; con Jerez, donde constan mercaderes toledanos vendiendo paños; con la actual Extremadura, que surtía de productos agropecuarios y se proveía de textiles; o, muy en especial, con Granada y los intereses de diverso signo alrededor de la seda. Una prolongación más hacia el oeste, sin embargo, implicó el comercio mantenido por Toledo con Portugal ${ }^{36}$. En conclusión, si sumamos estos últimos espacios a los que he subrayado desde las letras de cambio valencianas,

\footnotetext{
${ }^{34}$ Abed Al-Hussein 1986, p. 54.

${ }^{35}$ Quizá esta escasez pueda sorprender en el caso de Sevilla, otro de los grandes centros económicos hispanos de la segunda mitad del siglo XV. Pero es cierto que los efectos allí de la actividad toledana se notan más en el Quinientos que en el Cuatrocientos, a través en particular de la venta de tejidos procedentes de las coronas de Castilla (Toledo, Cuenca, Segovia, Ávila, Valladolid, Murcia y Granada) y Aragón (Zaragoza y Valencia). Al respecto, véase lo indicado en Igual, en prensa b, a partir de los trabajos nuevamente de Enrique Otte. Estas impresiones se confirman en una reciente obra sobre los comerciantes de Sevilla, donde las menciones a toledanos son realmente pobres (Perez 2016, pp. 100-101 y 175).

${ }^{36}$ Puñal 2014, pp. 126-128 (sobre Madrid); Munuera 2010, pp. 478, 681 y 691, y Rodríguez 1995, pp. 83-90 (sobre Murcia); Bello 2014, p. 24 (sobre Jerez); Clemente 2007, pp. 274-287
} 
surge la imagen de unos operadores presentes en numerosas áreas ibéricas, en particular desde el entorno del Duero hacia el sur, con independencia del grado de intensidad y estabilidad que dieran a sus negocios en ellas.

\section{VARIEDAD Y AMBIVALENCIAS DE LAS RELACIONES ENTRE COMERCIANTES}

Como es lógico, el propio desenvolvimiento de la cotidianidad de los mercados facilitó la relación de los toledanos con comerciantes de distintos orígenes, aunque solo fuera porque estos figuraban como contrapartes en los múltiples contratos que gestionaron. De nuevo las letras de cambio son muy sintomáticas al respecto, debido a los cuatro vértices operativos que contemplaban. Si nos referimos otra vez al sondeo efectuado desde Valencia, los pormenores completos de las letras que corresponden en el apéndice a Medina del Campo, Sevilla y Toledo ${ }^{37}$, por ejemplo, describen a unos mercaderes de Toledo en tratos directos o indirectos con más toledanos y con gentes de la Corona de Aragón y del resto de Castilla, pero también con toscanos, ligures y lombardos. No obstante, continuando con el apéndice, creo que es más significativo encontrar a toledanos en titularidades compartidas entre dos o más individuos, sobre todo cuando alguno de ellos no era toledano. Se deducen así determinados niveles asociativos, aunque no siempre sea posible profundizar en su contenido y sus características.

Francisco de la Torre es el personaje de quien he localizado más letras en mi sondeo. Recuerdo que los de la Torre eran una de las familias importantes de la diáspora comercial toledana. A varios de sus miembros entre el XV y el XVI los he citado ya en el artículo, incluyendo al mismo Francisco. Este parece ser entonces un mercader destacado dentro de la parentela, si atendemos a la cantidad de noticias y actividades que he logrado recoger de él, empezando por las 18 letras y las seis titularidades de cambios en que intervino de 1488 a 1499, según los datos del cuadro final. En esas titularidades, Francisco asumió un par en solitario en Toledo (1488) y en Valencia (1494-1499). Pero las otras cuatro lo presentan en Valencia en combinación con otros mercaderes, toledanos (con Diego de Acre en 1497 y con Alonso de la Torre en 1498) o no (con el valenciano Lluís Valleriola en 1494 y con el sienés Battista Bulguerini en 1497). Estamos delante, pues, de un sujeto que exhibe inicialmente relaciones de negocio plurales, lo que se ve certificado a

(sobre Extremadura); Martz 2001, y Soria 2016, pp. 418-424 (sobre Granada); Medrano 2007, pp. 352-353 (sobre Portugal).

${ }^{37}$ Tales pormenores pueden comprobarse en Igual 1997, pp. 147-151; Igual, Navarro 1997, pp. 329-332. 
lo largo del conjunto de su periplo vital y económico. Un periplo, además, en cuyo transcurso afloró el problema de su condición judeoconversa.

Alude a nuestro mercader la declaración que su mujer, Úrsula, realizó en 1506 ante la Inquisición en Valencia. Esta Úrsula, judeoconversa también, comunicaba que desconocía si su marido, Francisco de la Torre, había abjurado del judaísmo. La misma documentación inquisitorial (que es, lo repito, de 1506) permite saber que Francisco, natural de Toledo, era hijo de Fernando de la Torre y hermano de otro Fernando de la Torre; que tenía 34 años, lo que significa que había nacido en 1472; que se había casado con la tal Úrsula, hija del difunto mercader converso valenciano Dionís Rossell; y que tenía dos hijos: Juan, de 13 años, y Álvaro, de $10^{38}$.

Si aceptamos como cierto el nacimiento de Francisco en 1472, las primeras informaciones suyas que he registrado se encuadrarían en los comienzos de su carrera mercantil. En 1488, con el sobrenombre de "el mozo" (tendría 16 años), Francisco giró desde Toledo una letra de cambio dirigida a Valencia ${ }^{39}$. En 1493, con 21 años y como criado del famoso converso segoviano Fernán Núñez Coronel, fue testigo en Zaragoza del otorgamiento de un poder $^{40}$. Finalmente, en 1494, con 22 años, recibió en Valencia una letra de Villalón, escrita por otro Núñez Coronel (Pedro). En esta es donde Francisco consta asociado -como beneficiario en Valencia- al mercader local Lluís Valleriola, posiblemente converso, mientras que su corresponsal en Villalón fue el mercader toledano Sancho Ortiz ${ }^{41}$.

A partir de 1493-1494 menudean los datos de su actividad en Valencia, justamente. Su hijo mayor, Juan, debió nacer aquí hacia 1493. Es el que había tenido con la valenciana Úrsula y que, si damos la razón a las declaraciones inquisitoriales, contaba con 13 años en 1506. Sea como fuere, desde 1493-1494 y hasta 1499 en Valencia, Francisco de la Torre se muestra interesado por el tráfico de paños y sedas y llega a representar en la ciudad a otros mercaderes toledanos: a sus hermanos Álvaro y Fernando de la Torre en 1493 y a Alonso Husillo en 1494². Asimismo, cómo no, administró letras

${ }^{38}$ Cruselles, Cruselles, Bordes 2015, pp. 330 y 479-480.

${ }^{39}$ ARV, Protocolos, $n^{\circ} 2005$ (1488-XII-15). Tanto esta letra como las otras de Francisco de la Torre que argumentaré en lo sucesivo aparecen también en el cuadro del apéndice final.

${ }^{40}$ Ortego 2015, p. 419.

${ }^{41}$ ARV, Protocolos, n ${ }^{\circ} 2694$ (1494-VI-5). Un Lluís Valleriola mereció la atención de la Inquisición (Cruselles, Cruselles, Bordes 2015, p. 209). Sobre la condición conversa durante el XV de algunos Valleriola, mercaderes valencianos, véase Hinojosa 2012-2014, pp. 200 y 214. Más allá de su carácter religioso, Lluís Valleriola se mostró muy implicado en los intereses de los mercaderes toledanos en Valencia, como se verá después y como se señala también en Igual, en prensa a.

${ }^{42}$ Igual, en prensa a (sobre el tráfico textil y la representación de sus hermanos); ARV, Protocolos, nº 2012 (1494-V-12: sobre la representación de Alonso Husillo). 
como pagador y beneficiario, ya fuera individualmente o con las restantes titularidades combinadas que he comentado (con Diego de Acre, Alonso de la Torre o Battista Bulguerini). Estas letras se le enviaron desde Alcalá de Henares, Medina del Campo, Segovia, Sevilla, Requena y Toledo, aparte de la citada de Villalón, y en ellas se repite la típica variedad de operadores que manejaron los negocios: sustancialmente valencianos, castellanos e italianos de diversas procedencias. Con todo, en esta oportunidad, quienes fueron corresponsales cambiarios directos de Francisco de la Torre en esos lugares, esto es, con quienes este mantuvo lazos de delegación o representación, fueron muy mayoritariamente mercaderes toledanos: junto al reseñado Sancho Ortiz de Villalón, otros de la Torre (Juan y Alonso), de la Fuente (Diego), Husillo (Fernando) y San Pedro (Juan), por separado o conjuntamente ${ }^{43}$. Debió ser la radicación de la vida familiar y comercial de Francisco en Valencia, u otros motivos que ignoro, los que condujeron a nuestro mercader a avecindarse en esta capital el 2 de junio de $1498^{44}$.

A inicios del siglo XVI, Francisco de la Torre y su hermano Fernando participaron en la compañía que ya conocemos para el comercio ToledoValencia, que se disolvió en 1513 y cuyos otros socios eran también toledanos: Alonso Sánchez de Toledo, Lope García de Acre y Francisco de la Fuente ${ }^{45}$. Pertenece probablemente a esta empresa la deuda de 6.765 maravedís que se confesó en 1511, en Medina de Rioseco, a Alonso Sánchez de Toledo y Francisco de la Torre. En esta obligación, a Francisco de la Torre se le identifica ya como mercader vecino de Valencia ${ }^{46}$. La misma definición se le otorga en nuevos documentos notariales de Medina del Campo entre 1515 y 1519 , cuando tendría entre 43 y 47 años. Algunos parecen suponer una cierta prolongación hasta 1515 de los negocios de la extinta compañía, porque implicaron pagos que tenían que realizarse al propio Francisco de la Torre y a García de Acre e Inés Núñez, viuda de Alonso Sánchez de Toledo ${ }^{47}$. Los restantes, por el contrario, vuelven a situar a Francisco como tratante en Valencia de cambios girados con Medina del Campo en 1515 y 1519. También de nuevo, su círculo

${ }^{43}$ ARV, Protocolos, no 2694 (1494-VIII-14: hay dos, IX-9 y X-2), 2696 (1496-I-7 y XII-12), 2013 (1496-III-1), 2697 (1497-X-2 y 9) y 2698 (1498-II-8, III-1, IV-18 y VIII-21 y 1499-VII-5: hay tres).

${ }^{44}$ AMV, Llibres d'Aveïnaments, b3-8 (1498-VI-2). Ese mismo día también se convirtió en vecino de Valencia el toledano Fernando de la Torre, seguramente el hermano de Francisco. Si el acto de avecindamiento califica a Francisco como "mercader", en el caso de Fernando no incluye ninguna atribución profesional.

${ }^{45}$ Véase el párrafo final del apartado 2 del artículo.

${ }^{46}$ AHPV, Protocolos notariales, ${ }^{\circ} 8438$, f. 51r (1511-VIII-27).

${ }^{47}$ Carvajal, et al. 2015, pp. 263 (doc. 2389: 1515-VI-30), 270 (doc. 2459: 1515-VII-3), 275 (doc. 2521: 1515-VII-4) y 303 (doc. 2851: 1515-VII-12); Rozas, en prensa. 
de relaciones en estos cambios fue mayoritariamente toledano y hasta un viejo conocido, Sancho Ortiz, comparece otra vez en 1519 como su corresponsal cambiario $^{48}$.

Durante estas fechas del XVI, como vemos, Francisco de la Torre se había convertido en una especie de puente de conexión en Valencia del comercio toledano que pasaba por las ferias medinenses. En cualquier caso, la reiteración tras 1500 del universo toledano que acostumbraba a rodearlo en sus actividades no debe hacernos olvidar cómo Francisco diversificó ese universo a través de contactos, personales y económicos, con operadores de orígenes distintos. Así, a la postre, fue una dualidad de impulsos hacia dentro y hacia fuera del grupo de mercaderes de Toledo la que le permitió construir su red de relaciones. En la época, no es el único ejemplo en este sentido. También dos de los mercaderes que ya he nombrado (el toledano Sancho Ortiz y el valenciano Lluís Valleriola) y un tercer agente toledano (Juan Martínez Cabal) constituyeron compañías entre 1493 y 1495 en Valencia, y al menos Valleriola representó en la ciudad a sus socios y compartió con Ortiz la titularidad de un cambio ${ }^{49}$.

Pese a todo, hay que admitir que el mundo toledano de los negocios en el exterior brinda a veces un aspecto de relativo cierre sobre sí mismo. Esta imagen se justificaría por la consistencia que se suele apreciar en los vínculos económicos y empresariales entre los propios toledanos y, en paralelo, por los múltiples e intrincados lazos de consanguinidad que les unían con frecuen$\mathrm{cia}^{50}$. Es como si, por usar la expresión con que Enrique Soria se ha referido a los toledanos de la Granada del Quinientos, estos mercaderes conformaran al final "una gran familia, con cientos de ramificaciones" ${ }^{51}$. El citado cierre, de ser auténtico, podría estimarse basado en las estructuras familiares amplias de los toledanos y, quizá, en la búsqueda de factores de autoprotección ante las consecuencias del hecho judeoconverso y de la acción de la Inquisición. Pero, puesto que me centro en los toledanos lejos de su ciudad, dicho cierre hipotético también radicaría en una lógica habitual en los procesos de expansión mercantil: la seguridad y la confianza que proporcionaba fuera el quedar rodeado por los más cercanos y conocidos.

Un posible efecto de esta circunstancia sería la homogeneidad grupal que cabría detectar entre los toledanos, más allá de la cohesión que podía

${ }^{48}$ Carvajal, et al. 2015, pp. 410 (doc. 4163: 1515-XI-29) y 606-607 (docs. 6192-6194: 1519XII-4/6).

${ }^{49}$ Igual, en prensa a; ARV, Protocolos, no 2010 (1493-II-16 y 25 y X-26) y 2012 (1494-V28). La titularidad cambiaria de Ortiz-Valleriola figura, en Valencia, en el cuadro del apéndice final.

${ }^{50}$ Estos puntos se han observado también en el apartado 2 del artículo.

${ }^{51}$ Soria 2016, pp. 424-425. 
darles su procedencia común. Este fenómeno es reflejado en ocasiones por las propias fuentes: por ejemplo, cuando algún documento valenciano de finales del siglo XV llega a hablar genéricamente de els toledans o de los mercaders toledans $^{52}$. Cuestión diferente es la consideración del grupo en términos de potencialidad y jerarquía, sobre todo con respecto a colectivos mercantiles ajenos. Desde luego, en el comercio de Toledo como en cualquier otro, la heterogeidad de estructuras, recursos y capitales era la norma. Pero, como ya he anotado al inicio, entre los toledanos fuera de Toledo debían predominar los mercaderes medianos y grandes, lo que otorgaría al grupo -también desde esta perspectiva- un sustrato bastante uniforme y capaz de ser comparado.

De entrada, las colaboraciones que he venido señalando entre mercaderes toledanos y no toledanos (recuerdo las principales: ser contrapartes en los negocios, compartir titularidades cambiarias, llegar a formar empresas mixtas, ejercer tareas de representación o establecer lazos familiares), por pocas o numerosas que sean, sitúan a los primeros bien integrados en el contexto comercial del periodo y confirman que poseían capacidades y desarrollaban estrategias, sociales y económicas, equiparables a muchos de los que concurrían con ellos en los mercados. No obstante, tampoco faltaron entre toledanos y no toledanos los motivos de conflicto, que sirven asimismo para revelar elementos significativos por lo que concierne a los contrastes entre grupos. De hecho, al final de la etapa que me interesa, entre 1514 y 1523, esos motivos convergieron en Medina del Campo al registrarse en la villa cuantiosas bancarrotas mercantiles que afectaron, en gran medida, a compañías de Toledo.

Algunas de estas quiebras, fundamentalmente de 1519-1521, pueden conectarse con las alteraciones sufridas por Castilla durante la revuelta comunera. Pero, aparte, no sería extraño que la exposición al endeudamiento crediticio y el encadenamiento de impagos entre las mismas compañías, con repercusiones en la propia capital toledana, estuvieran también en la base de la ruina de bastantes mercaderes. En tales quiebras llama la atención que, entre los acreedores de los toledanos con problemas, solían hallarse mercaderes de Burgos. Estos figuraban entonces en Medina como un sector dominante y con suficiente capacidad económica para competir y lograr imponerse a otros operadores mediante préstamos de dinero, como sucedió al parecer con los de Toledo a inicios del $\mathrm{XVI}^{53}$.

${ }^{52}$ ARV, Protocolos, $\mathrm{n}^{\circ} 2003$ (1484-II-5). Ambas expresiones constan aquí, en el protesto de una letra de cambio enviada de Córdoba a Valencia y dirigida al cambista valenciano Lluís Serra, "la hu dels interessats dels toledans". El dinero de la letra debía cargarse "als deu obligats per les fahenes dels interessats per los mercaders toledans".

${ }^{53}$ Abed Al-Hussein 1986, pp. 57 y 228-233; Igual, en prensa b. Documentos de 1519, demostrativos de las quiebras y de las deudas de toledanos a burgaleses, se encuentran en AHPV, Protocolos notariales, $\mathrm{n}^{\circ}$ 7840, ff. 466r-467v y 590r-593v. 
Si traigo a colación estos episodios es porque, en el fondo, la supremacía puntual acreditada entre burgaleses y toledanos sería el síntoma de una cierta jerarquía más global. Sin duda, entre los mercaderes de Toledo había personajes de gran relieve. Pero, en comparación, los niveles obtenidos por los mercaderes de Burgos entre el XV y el XVI en cuanto a fortuna, complejidad y solidez empresariales y dilatación territorial de negocios debieron resultar normalmente inalcanzables para los toledanos. En el plano espacial, por ejemplo, la expansión de los burgaleses a escala hispánica y europea choca con la de unos toledanos más restringida, como he explicado, a la Península Ibérica. Las razones de estas diferencias y de las dinámicas que llevaron a limitar las expectativas de los toledanos son variadas y no me detengo en ellas $^{54}$. Creo más importante recalcar que la desigualdad entre unos y otros pudo concretarse incluso en una división de funciones. Si los burgaleses se dedicaron a colocar en la península productos de importación como paños y lienzos, los segundos llegaron a cubrir como minoristas la distribución interna en el reino castellano de parte de tales productos, que eran muchas veces de alta calidad y precio y se destinaban a una clientela aristocrática distinguida y selecta ${ }^{55}$.

\section{CONCLUSIONES}

El artículo comenzó con una visión general de las características con las que se concretó la presencia mercantil toledana fuera de su ciudad, centrándome en los factores familiares y societarios y el desarrollo de determinadas trayectorias personales. Con bases como estas, los toledanos del final del Medievo dieron pie a una distribución territorial de negocios a la que, después, me aproximé microanalíticamente mediante una documentación específica: un fondo de letras de cambio llegadas a Valencia durante el periodo 1475-1500. De todo ello derivó un conjunto variado de relaciones con otros grupos mercantiles, que examiné en último lugar también desde ejemplos esencialmente valencianos, aunque no solo, y que podrían considerarse sintomáticas de la posición -en ocasiones jerarquizada- que acabaron ocupando los toledanos en el mundo económico hispánico.

En medio de este recorrido he pretendido dar cuenta de una serie de aspectos que, por un lado, serían similares entre los mercaderes toleda-

\footnotetext{
${ }^{54}$ Aparecen comentadas en Igual, en prensa b. Sobre los mercaderes burgaleses y las características de su expansión, es imprescindible recurrir a los trabajos de Hilario Casado, como los que he mencionado ya en páginas anteriores.

${ }^{55}$ Tomo esta hipótesis de Caunedo 1983,p. 141.
} 
nos y sus colegas coetáneos y, por el otro, de manera más o menos segura o hipotética, manifestarían ciertas particularidades de los primeros. Pero, sobre todo, he procurado reflejar diversas perspectivas que ayudan a describir $\mathrm{y}$, en su caso, explicar la proyección mercantil toledana: las territoriales y, muy en especial, las sociales y las económicas. Con respecto a estas dos últimas, y en consonancia con lo que viene corroborando la historiografía reciente, cada vez están más claras las imbricaciones entre lo social y lo económico, hasta el punto de que a veces resulta complicado distinguir ambos elementos. Entre los toledanos, los vínculos familia-empresa, sus efectos sobre la vertebración de los negocios y sobre el establecimiento de círculos de relación e, incluso, la posible influencia del hecho judeoconverso sobre las realidades acreditadas serían algunas de las circunstancias que demostrarían las citadas imbricaciones.

A la postre, todo se plasmó en una actuación de las gentes de Toledo que, lo reitero, quedó focalizada en el interior de la Península Ibérica y, aún más, en núcleos que ostentaron en el paso del XV al XVI una categoría destacada en el comercio y las finanzas hispanas. En esa línea iría el papel que se ha subrayado en el artículo de ámbitos como Toledo, Medina del Campo o Valencia, que son en los que parece concentrarse entonces la atención de los toledanos. Estas imágenes adquieren significado si las comparamos con la geografía económica de otros grupos mercantiles. No lo digo solo por el contraste espacial, ya indicado, entre los radios de intervención burgalés y toledano. En la etapa por ejemplo de los Reyes Católicos, los italianos presentes en la península, partiendo obviamente de una implantación de escala euromediterránea, dibujaron esquemas de actividad también diferenciados: para los ligures, buena parte de sus movimientos se desparramó en el eje Valencia-Sevilla; para los toscanos, por el contrario, fue el cuadrilátero Valencia-Sevilla-Lisboa-Medina del Campo el de mayor alcance ${ }^{56}$. Así, los mapas de negocio trazados por cada colectivo mercantil podían diseñar jerarquías diversas dentro de los centros comerciales y financieros de la época.

Siguiendo con este marco comparativo para concluir, la restricción de los intereses toledanos a la península podría considerarse en efecto la señal de una mercatura situada algún escalón por debajo de la promovida desde otros grupos. No obstante, por lo menos el número (importante) de mercaderes de Toledo que estuvo fuera de su ciudad y los rasgos (complejos y dispersos) de su presencia externa les otorgaron funciones no desdeñables en la construcción del panorama socioeconómico de los reinos hispánicos en el entorno de 1500. Además, la repercusión documental de sus actividades en un núcleo

${ }^{56}$ Igual 2007b, pp. 161-165. 
de la significación de Valencia no fue precisamente menor, como se habrá observado, incluso aunque la posición de los toledanos en algún negocio valenciano pudiera calificarse de secundaria en relación con la de otros mercaderes. Todo supone, pues, una invitación a continuar con las investigaciones, ya sea en los propios archivos de Valencia, ya sea en otros fondos documentales.

\section{APÉNDICE: TITULARES TOLEDANOS DE CAMBIOS, SEGÚN LAS LETRAS REPRODUCIDAS EN VALENCIA EN LOS REGISTROS DEL NOTARIO JAUME SALVADOR $(1475-1500)^{57}$}

\begin{tabular}{|c|c|c|c|}
\hline LUGARES & TITULARES & AÑOS & LETRAS \\
\hline $\begin{array}{c}\text { Alcalá de } \\
\text { Henares }\end{array}$ & Torre, Alonso de la, y Fuente, Diego de la & 1497 & 1 \\
\hline Barcelona & Castro Espanoche, Alonso de $\mathrm{d}^{58}$ & 1493 & 1 \\
\hline Burgos & Torre, Alonso de la, y Fuente, Diego de la & 1497 & 1 \\
\hline $\begin{array}{c}\text { Medina de } \\
\text { Rioseco }\end{array}$ & $\begin{array}{l}\text { Gutiérrez de la Caballería, Alonso (de Almagro), y } \\
\text { Castro, Alonso de }{ }^{59}\end{array}$ & 1497 & 1 \\
\hline
\end{tabular}

${ }^{57}$ En el cuadro, la primera columna incluye los lugares donde operaban los toledanos localizados. La segunda ofrece la lista de dichos toledanos, por orden alfabético de apellidos y con la denominación como titulares que se les atribuye en las letras de cambio. Si hay individuos no toledanos, su origen se indica de manera explícita. La tercera columna reproduce los años en que cada titularidad ha sido detectada, según las fechas de emisión de los cambios. La cuarta contabiliza el número de letras en que cada una de las titularidades interviene. Creo conveniente aclarar que, a la hora de identificar a los toledanos en la documentación consultada, he procurado ser lo más estricto posible. Así, para evitar errores que fueran fruto de la homonimia con otros castellanos, me he limitado a considerar los operadores sobre los que las fuentes y la bibliografía usadas para este trabajo señalaran su carácter toledano con claridad o, al menos, como hipótesis muy probable.

58 Pablo Ortego demuestra que este personaje es vecino de Toledo y acepta que sea el Alonso de Castro, de Salamanca, que durante la década de 1480 representó en Valencia al banco sienés de los Spannochi (Igual 2007a, p. 341). De ahí que pudiera incorporar el sobrenombre "Espanoche" a su denominación personal (Alonso de Castro), quizá como mecanismo de reputación y de ratificación del nexo que le unía a los italianos (Ortego 2014, pp. 405 y 407).

59 En el cuadro, esta titularidad se repite en Medina del Campo y en Toledo. De nuevo Pablo Ortego confirma para la época (años noventa del siglo XV) el contacto de los dos operadores que se citan en negocios y cambios. También este autor testimonia: 1) que Alonso Gutiérrez de la Caballería era vecino de Almagro; 2) que Alonso de Castro se corresponde en realidad con el Alonso de Castro Espanoche a que he aludido en la nota anterior; 3) que Gutiérrez de la Caballería era suegro de Alonso de Castro (Ortego 2014, pp. 384 y 404-410). 


\begin{tabular}{|c|l|c|c|}
\hline LUGARES & \multicolumn{1}{|c|}{ TITULARES } & AÑOS & LETRAS \\
\hline \multirow{4}{*}{$\begin{array}{c}\text { Medina } \\
\text { del Campo }\end{array}$} & Alonso, Esteban & 1494 & 1 \\
\cline { 2 - 4 } & Castro, Alonso de ${ }^{60}$ & 1495 & 1 \\
\cline { 2 - 4 } & Fuente, Alonso de la & 1488 & 2 \\
\cline { 2 - 4 } & Fuente, Diego de la, y Torre, Juan de la & 1493 & \\
\cline { 2 - 4 } & Gutiérrez, Alonso (de Almagro/Madrid), y Castro, & 1494 & 1 \\
\cline { 2 - 4 } & Alonso de ${ }^{61}$ & & 3 \\
\cline { 2 - 4 } & Gutiérrez de la Caballería (de Almagro), Alonso, y & 1496 & 3 \\
\cline { 2 - 4 } & Castro, Alonso de & 1497 & \\
\cline { 2 - 4 } & Hurtado, Fernando & 1488 & 1 \\
\cline { 2 - 4 } & Husillo, (...) & 1488 & 1 \\
\cline { 2 - 4 } & Husillo, Fernando & 1497 & 1 \\
\cline { 2 - 4 } & San Pedro, Alonso de & 1496 & 1 \\
\cline { 2 - 4 } & San Pedro, Gozalbo de & 1496 & 1 \\
\cline { 2 - 4 } & San Pedro, Juan de & 1492 & 5 \\
\cline { 2 - 4 } & & 1493 & \\
\cline { 2 - 4 } & & 1497 & \\
\cline { 2 - 4 } & Scalia, Battista (de Génova), y Hurtado, Luis & 1497 & 1 \\
\cline { 2 - 4 } & Torre, Juan de la & 1494 & 2 \\
\cline { 2 - 4 } & Torre, Juan y Alonso de la & 1496 & 2 \\
\cline { 2 - 4 } & Torre, Juan y Alonso de la, y Fuente, Alonso de la & \\
\hline \multirow{2}{*}{} & & \\
\hline
\end{tabular}

${ }^{60}$ En el cuadro, esta titularidad se repite en Toledo. En las letras en que interviene este agente, actúa -en Toledo- como corresponsal cambiario de los sieneses Spannochi o -en Medina del Campo- con un círculo de relaciones similar al empleado en ocasiones por la titularidad de Alonso Gutiérrez de la Caballería y Alonso de Castro. Por tanto, el Alonso de Castro de este ítem debe tratarse también del Alonso de Castro Espanoche que he mencionado en las dos notas previas. Aparte, sabemos que siempre este Alonso de Castro Espanoche gestionó cambios junto a Sancho de Toledo en el decenio de 1490 (Ortego 2014, p. 407), y, precisamente, como ya he alegado en algún momento del artículo, a Sancho de Toledo y Alonso de Castro, de Toledo, se les debía computar una letra remitida en 1493 de Sevilla a Valencia (ARV, Protocolos, no 2692 $-1493-\mathrm{X}-26-)$.

${ }^{61}$ Continuando con Alonso de Castro (Espanoche), sus actividades lo vincularon a Alonso Gutiérrez de la Caballería (de Almagro) y a Alonso Gutiérrez de Madrid, tesorero general de la Hermandad entre 1493 y 1499 y que, pese a su apellido toponímico, puede ser oriundo de Toledo, de donde llegó a ser vecino y regidor (Ortego 2014, pp. 385, 401-410, 415 y 417). En esta titularidad cambiaria, el hecho de que Alonso Gutiérrez aparezca así, sin ningún añadido nominal más, impide decidir si se trata de uno (el de Almagro) o del otro (el de Madrid). Por tanto, prefiero por ahora separarla de las letras donde figura Alonso Gutiérrez de la Caballería. Y ello, mucho más cuando, en las propias fuentes valencianas, también se atestigua algún movimiento financiero de Alonso Gutiérrez de Madrid, tesorero. En concreto, en 1496 a través de una letra de Toledo a Valencia de la que este Gutiérrez fue prestamista en Toledo y cuyos beneficiarios en la capital mediterránea fueron criados suyos: Álvaro de Bonilla o Diego Vázquez de Jaén (ARV, Protocolos, nº 2013 -1496-IX-17-). 


\begin{tabular}{|c|c|c|c|}
\hline LUGARES & TITULARES & AÑOS & LETRAS \\
\hline Requena & Torres, Francisco de & 1499 & 1 \\
\hline Roma & Acre, Alonso de & $\begin{array}{l}1483 \\
1485\end{array}$ & 2 \\
\hline Segovia & Torre, Alonso de la (jurado de Toledo) & 1494 & 3 \\
\hline \multirow[t]{3}{*}{ Sevilla } & Fuente, Alonso y Diego de la & 1500 & 2 \\
\hline & Hernández o Fernández, Pedro & $\begin{array}{l}1494 \\
1495 \\
1498 \\
1499 \\
\end{array}$ & 4 \\
\hline & Torre, Alonso de la & 1500 & 1 \\
\hline \multirow[t]{11}{*}{ Toledo } & Castro, Alonso de & 1494 & 1 \\
\hline & Fuente, Rodrigo de la & 1477 & 1 \\
\hline & $\begin{array}{l}\text { Gutiérrez de la Caballería, Alonso (de Almagro), y } \\
\text { Castro, Alonso de }\end{array}$ & 1495 & 1 \\
\hline & Pérez, Alonso & 1496 & 1 \\
\hline & San Pedro, Nicolás de & 1492 & 1 \\
\hline & Toledo, Alonso de & 1487 & 1 \\
\hline & $\begin{array}{l}\text { Toledo, Juan de; Cárcel, Juan de la (el mozo); y } \\
\text { Husillo, Fernando }\end{array}$ & 1495 & 1 \\
\hline & Toledo, Pedro de & 1492 & 1 \\
\hline & Torre, Alonso de la (jurado de Toledo) & 1495 & 1 \\
\hline & Torre, Francisco de la (el mozo) & 1488 & 1 \\
\hline & Torre, Juan de la (el mozo) & 1498 & 1 \\
\hline \multirow[t]{10}{*}{ Valencia } & Acre, Diego de & $\begin{array}{l}1477 \\
1483 \\
\end{array}$ & 2 \\
\hline & Acre, Diego de, o Torre, Francisco de la & 1497 & 1 \\
\hline & Acre, Francisco de & 1485 & 1 \\
\hline & $\begin{array}{l}\text { Alcaraz, Alonso de (criado de Gozalbo de San } \\
\text { Pedro, en la posada de Diego López Jarada) }\end{array}$ & 1496 & 1 \\
\hline & Alonso, Esteban & 1494 & 1 \\
\hline & $\begin{array}{l}\text { Bulguerini, Battista (de Siena), o Torre, Francisco } \\
\text { de la }\end{array}$ & 1497 & 1 \\
\hline & Cota, Sancho (hijo del jurado Sancho Cota) & 1494 & 1 \\
\hline & Fuente, Juan de la & 1497 & 1 \\
\hline & Hurtado, Luis & 1488 & 1 \\
\hline & Husillo, Alonso, o Toledo, Alonso de & 1488 & 1 \\
\hline
\end{tabular}




\begin{tabular}{|c|c|c|c|}
\hline LUGARES & TITULARES & AÑOS & LETRAS \\
\hline & Jarada, Diego de & 1488 & 1 \\
\hline & López Jarada, Diego & 1496 & 1 \\
\hline & Ortiz, Sancho & 1488 & 1 \\
\hline & Ortiz, Sancho, o Valleriola, Lluís (de Valencia) & 1494 & 1 \\
\hline & Pérez, Alonso & 1497 & 1 \\
\hline & $\begin{array}{l}\text { Toledo, Alonso de; Hurtado, Luis; o Torrijos, } \\
\text { Alonso de }\end{array}$ & 1488 & 1 \\
\hline & Torre, Alonso de la & 1487 & 1 \\
\hline & Torre, Alonso de la, y Acre, Diego de & 1495 & 1 \\
\hline & Torre, Francisco de la & $\begin{array}{l}1494 \\
1495 \\
1496 \\
1497 \\
1499\end{array}$ & 13 \\
\hline & \begin{tabular}{|l|} 
Torre, Francisco y Alonso de la \\
\end{tabular} & 1498 & 1 \\
\hline & Torre, Francisco de la, o Valleriola, Lluís (de Valencia) & 1494 & 1 \\
\hline & Torres, Íñigo de & 1500 & 1 \\
\hline & Torrijos, Alonso (sedero) $)^{62}$ & 1496 & 1 \\
\hline Valladolid & Torre, Alonso de la (jurado de Toledo) & 1488 & 1 \\
\hline \multirow[t]{2}{*}{ Villalón } & Fuente, Juan de la & 1496 & 1 \\
\hline & Ortiz, Sancho & 1494 & 1 \\
\hline
\end{tabular}

Fuentes: ARV, Protocolos, no 1997 (1477-XI-13: titularidad en Toledo y Valencia), 2003 (1484-I-14: en Roma y Valencia), 2004 (1485-VII-20: en Roma y Valencia), 2675 (1487-VII-7: en Toledo y Valencia), 2676 (1488-VIII-16: en Valencia; XI-4: en Valencia y Valladolid), 2005 (1488-XII-15: en Toledo; XII-16: en Medina del Campo y Valencia), 2006 (1489-II-3, hay dos: en Medina del Campo y Valencia), 2690 (1492-VIII-27: en Medina del Campo; XI-27: en Toledo), 2692 (1493-II-1: en Toledo; X-2: en Medina del Campo; XI-4: en Barcelona), 2010 (1493-IX-11: en Medina del Campo), 2694 (1494-VI-2: en Toledo; VI-5: en Valencia y Villalón; VIII-13: en Valencia; VIII-14, hay dos: en Segovia y Valencia; IX-9: en Segovia y Valencia; IX-10: en Medina del Campo y Valencia; X-2: en Medina del Campo y Valencia; X-6: en Medina del Campo; XI-24: en Sevilla; XII-9: en Medina del Campo y Valencia), 2693 (1495-III-2: en Toledo y Valencia; VIII-5: en Medina del Campo; IX-15: en Sevilla), 2011 (1495-III-26: en Medina del Campo), 2696 (1496-I-7: en Toledo y Valencia; V-17: en Villalón; VIII-11: en Medina del Campo; X-3: en Medina del Campo y Valencia; X-5: en Medina del Campo; X-10: en Medina del Campo; X-12: en Valencia; XII-12, hay tres: dos en Medina del Campo y Valencia y una en Toledo), 2013 (1496-III-1: en Valencia; VIII-16: en Medina del Campo; XII-3: en Medina del Campo), 2697 (1497-IV-11: en Burgos; X-2: en Medina del Campo y Valencia; X-9: en Medina del Campo y Valencia; XI-20: en Medina de Rioseco), 2698 (1498-II-5: en Medina del Campo y Valencia; II-8: en Medina del Campo y Valencia; II-15: en Medina del Campo; III-1: en Alcalá de Henares y Valencia; IV-18: en Medina del Campo y Valencia; V-2: en Valencia; VIII-21: en Toledo y Valencia; 1499-II-6: en Sevilla; VI-8: en Sevilla; VI12: en Requena; VII-5, hay tres: en Valencia) y 2018 (1500-VII-4, hay tres: tres en Sevilla y una en Valencia).

${ }^{62}$ Es un toledano que se avecindó en Valencia en 1477. En la letra de cambio donde consta su titularidad, su apellido aparece como "Torriges", una forma habitual para este personaje en otras fuentes valencianas del periodo (Igual, en prensa, a). Es improbable que se trate del mismo Alonso de Torrijos que figura en otra titularidad en Valencia, mencionada antes en el cuadro. En este caso, Torrijos es citado dentro de una titularidad colectiva (Alonso de Toledo, Luis Hurtado y Alonso de Torrijos) y sus componentes son calificados como vecinos de Toledo. 


\section{BIBLIOGRAFÍA CITADA}

Abed al-Hussein, Falah Hassan (1986), El comercio de los géneros textiles: seda, paños y lienzos y Las quiebras de los hombres de negocios castellanos, en Lorenzo Sanz, Eufemio (coord.), Historia de Medina del Campo y su tierra, Valladolid, Ayuntamiento de Medina del Campo, vol. II, pp. 43-66 y 221-266, respectivamente.

Alonso García, David (2005), Entre Granada y Castilla. La familia Fuente y la hacienda real a comienzos de la Edad Moderna, "Investigaciones históricas. Época moderna y contemporánea" 25, pp. 11-30.

Bello León, Juan Manuel (2014), Mercaderes del siglo XV en Jerez de la Frontera, "Historia. Instituciones. Documentos" 41, pp. 11-44.

Carvajal de la Vega, David (2012), Crédito y préstamo entre mercaderes castellanos a fines de la Edad Media, en Bonachía Hernando, Juan Antonio; Carvajal de la Vega, David (eds.), Los negocios del hombre. Comercio y rentas en Castilla. Siglos XV y XVI, Valladolid, Castilla, pp. 53-76.

Carvajal de la Vega, David (2015a), En los precedentes de la banca castellana moderna: cambiadores al norte del Tajo a inicios del siglo XVI, en García Fernández, Ernesto; Bonachía Hernando, Juan Antonio (eds.), Hacienda, mercado y poder al norte de la Corona de Castilla en el tránsito del Medievo a la Modernidad, Valladolid, Castilla, pp. 17-37.

Carvajal de la Vega, David (2015b), Flujos financieros norte-sur en Castilla a fines de la Edad Media, "Anales de Historia Medieval de la Europa atlántica" 2, pp. 81-104.

Carvajal de la Vega, David; Herrero Jiménez, Mauricio; Molina de la Torre, Francisco J.; Ruiz Albi, Irene (2015), Mercaderes y cambiadores en los protocolos notariales de la provincia de Valladolid (1486-1520), Valladolid, Universidad de Valladolid.

Casado Alonso, Hilario (2012a), Crecimiento económico, redes de comercio y fiscalidad en Castilla a fines de la Edad Media, en Bonachía Hernando, Juan Antonio; Carvajal de la Vega, David (eds.), Los negocios del hombre. Comercio y rentas en Castilla. Siglos XV y XVI, Valladolid, Castilla, pp. 17-35.

Casado Alonso, Hilario (2012b), Comercio y hombres de negocios castellanos y navarros en los inicios de la "Primera Edad Global", en En los umbrales de España. La incorporación del Reino de Navarra a la monarquía hispana. XXXVIII Semana de Estudios Medievales (Estella, 18 a 22 de julio de 2011), Pamplona, Gobierno de Navarra, pp. 333-370. 
Casado Alonso, Hilario (2015), Circuitos comerciales y flujos financieros en Castilla a fines de la Edad Media e inicios de la Modernidad, en Estados y mercados financieros en el Occidente cristiano (siglos XIIIXVI). XLI Semana de Estudios Medievales (Estella, 15 a 18 de julio de 2014), Pamplona, Gobierno de Navarra, pp. 273-307.

Caunedo del Potro, Betsabé (1983), Un importante papel de los mercaderes de Toledo a finales del siglo XV: abastecedores de la casa real, "Anales toledanos" 16, pp. 139-149.

Clemente Ramos, Julián (2007), La actividad comercial en la tierra de Medellín (siglos XV-XVI), en Ferias y mercados en España y América. A propósito de la 550 Feria de San Miguel de Zafra, Zafra, Junta de Extremadura, pp. 265-293.

Cruselles Gómez, José María; Cruselles Gómez, Enrique; Bordes García, José (2015), Conversos de la ciudad de Valencia. El censo inquisitorial de 1506, Valencia, Institució Alfons el Magnànim.

González Arce, José Damián (2016), La casa y corte del príncipe don Juan (1478-1497). Economía y etiqueta en el palacio del hijo de los Reyes Católicos, Sevilla, Sociedad Española de Estudios Medievales.

Hinojosa Montalvo, José (2012-2014), Sederos conversos en la Valencia bajomedieval, "Anales de la Universidad de Alicante. Historia Medieval" 18 , pp. 187-224.

Igual Luis, David (1996), Valencia e Italia en el siglo XV. Rutas, mercados y hombres de negocios en el espacio económico del Mediterráneo occidental, vol. III, Valencia, Universidad de Valencia (tesis doctoral, edición en formato de microficha).

Igual Luis, David (1997), Los mercaderes italianos y las relaciones económicas entre Valencia y Castilla en el siglo $X V$, en $X V$ Congreso de Historia de la Corona de Aragón (Jaca, 1993), Zaragoza, Gobierno de Aragón, vol. II, pp. 135-151.

Igual Luis, David (1998), Valencia e Italia en el siglo XV. Rutas, mercados y hombres de negocios en el espacio económico del Mediterráneo occidental, Castellón, Bancaixa - Comité Econòmic i Social de la Comunitat Valenciana (tesis doctoral, edición en formato de libro).

Igual Luis, David (2007a), Sieneses en la Valencia bajomedieval. Los Spannochi y sus representantes empresariales, en Ascheri, Mario; Nevola, Fabrizio (a cura di), L'ultimo secolo della Repubblica di Siena. Politica e istituzioni, economia e società, Siena, Accademia Senese degli Intronati, pp. 333-360.

Igual Luis, David (2007b), Banqueros y comerciantes italianos en España en tiempos de los Reyes Católicos, en Casado Alonso, Hilario; García-Baquero, Antonio (eds.), Comercio y hombres de negocios en 
Castilla y Europa en tiempos de Isabel la Católica, Madrid, Sociedad Estatal de Conmemoraciones Culturales, pp. 151-180.

Igual Luis, David (en prensa, a), Mercaderes castellanos y fiscalidad en Valencia (1487-1513), en Homenaje al Profesor José Hinojosa Montalvo, Alicante, Universidad de Alicante.

Igual Luis, David (en prensa, b), Los espacios y los protagonistas de la economía mercantil regional, en Asenjo González, María (coord.), Villas y ciudades a finales de la Edad Media. El potencial urbano del ámbito sudoriental de Castilla-La Vieja, Madrid, Sílex.

Igual Luis, David; Navarro Espinach, Germán (1997), Los genoveses en España en el tránsito del siglo XV al XVI, "Historia. Instituciones. Documentos" 24, pp. 261-332.

Ladero Quesada, Miguel Ángel (1987), El banco de Valencia, los genoveses y la saca de moneda de oro castellana. 1500-1503, "Anuario de Estudios Medievales"17, pp. 571-594.

Ladero Quesada, Miguel Ángel (2010), Ciudades de la España medieval. Introducción a su estudio, Madrid, Dykinson.

Ladero Quesada, Miguel Ángel (2017), España a finales de la Edad Media: 1. Población. Economía, Madrid, Dykinson.

López Gómez, Óscar (2007), La sociedad amenazada. Crimen, delincuencia y poder en Toledo a finales del siglo XV, Toledo, Ayuntamiento de Toledo.

Martz, Linda (1988), Converso Families in Fifteenth and Sixteenth-Century Toledo: The Significance of Lineage, "Sefarad" 48/1, pp. 117-196.

Martz, Linda (2001), Los toledanos y el reino de Granada, de 1492 a la década de 1560, en Kagan, Richard L.; Parker, Geoffrey (eds.), España, Europa y el mundo Atlántico. Homenaje a John H. Elliott, Madrid, Marcial Pons, pp. 151-176.

Martz, Linda (2002), A Network of Converso Families in Early Modern Toledo: Assimilating a Minority, Michigan, The University of Michigan Press.

Medrano Fernández, Violeta (2007), El comercio terrestre castellano-portugués a finales de la Edad Media: infraestructuras de apoyo a la actividad comercial y mercaderes, "Edad Media. Revista de Historia" 8, pp. 331-356.

Munuera Navarro, David (2010), Musulmanes y cristianos en el Mediterráneo. La costa del sureste peninsular durante la Edad Media (ss. VIIIXVI), Murcia, Universidad de Murcia (tesis doctoral).

Orlandi, Angela (2016), Le prestazioni di una holding tardo medievale rilette attraverso alcune teorie di management e la Social Network Analysis, en Innovare nella storia economica: temi, metodi, fonti. Atti del 
convegno della Società Italiana degli Storici Economici (Università Roma 3, 10-11 ottobre 2014), Prato, Fondazione Istituto Internazionale di Storia Economica "F. Datini", pp. 117-148.

Ortego Rico, Pablo (2014), Alonso Gutiérrez de Madrid y otros agentes financieros de Castilla la Nueva en la tesorería general de la Hermandad (1493-1498): vínculos cooperativos, redes socioeconómicas y gestión fiscal, "Espacio, Tiempo y Forma. Serie III: Historia Medieval" 27, pp. 381-420.

Ortego Rico, Pablo (2015), Poder financiero y gestión tributaria en Castilla: los agentes fiscales en Toledo y su reino (1429-1504), Madrid, Universidad de Málaga - Instituto de Estudios Fiscales.

Otte, Enrique (1986), Il ruolo dei genovesi nella Spagna del XV e XVI secolo, en De Maddalena, Aldo; Kellenbenz, Hermann (a cura di), La repubblica internazionale del denaro tra XV e XVII secolo. Atti della Settimana di Studio, 17-22 settembre 1984, Bolonia, Il Mulino, pp. 17-56.

Perez, Béatrice (2016), Les marchands de Séville. Une société inquiète (XVe$X V I^{e}$ siècles), París, Presses de l'Université Paris-Sorbonne.

Puñal Fernández, Tomás (2014), El comercio madrileño en el entorno territorial y urbano de la Baja Edad Media, "Edad Media. Revista de Historia" 15, pp. 115-133.

Rodríguez Llopis, Miguel (1995), La integración del Reino de Murcia en el comercio europeo al fin de la Edad Media, en Casado Alonso, Hilario (ed.), Castilla y Europa. Comercio y mercaderes en los siglos XIV, XV y XVI, Burgos, Diputación Provincial, pp. 81-114.

Rozas Español, Ángel (en prensa), Los conversos toledanos en los mercados peninsulares de la seda entre 1490-1520. ¿Una identidad económica?, en Identity Economics. A Comparative Perspective on the Crown of Aragon and the Low Countries (13th-16th Centuries). International Colloquium (Zaragoza, 7-8 June 2017), Zaragoza, Universidad de Zaragoza.

Ruiz Martín, Felipe (1995), Orígenes del capitalismo en Castilla, en Ribot García, Luis Antonio; Carrasco Martínez, Adolfo; Adão da Fonseca, Luis (coords.), El Tratado de Tordesillas y su época. Congreso Internacional de Historia (Setúbal, Salamanca y Tordesillas, 2-7 de junio de 1994), Valladolid, Junta de Castilla y León, vol. I, pp. 177-196.

Soria Mesa, Enrique (2016), El negocio del siglo. Los judeoconversos y la renta de la seda del Reino de Granada (siglo XVI), "Hispania" 76/253, pp. 415-444.

Fecha de recepción del artículo: octubre 2017

Fecha de aceptación y versión final: marzo 2018 